\author{
Umur Işık \\ Gazi University, umur@gazi.edu.tr, Ankara-Turkey \\ Konur Alp Koz \\ Gazi University, kalpkoz@gmail.com, Ankara-Turkey
}

\author{
http://dx.doi.org/10.12739/NWSA.2014.9.2.4C0178
}

\title{
ÇÖP YIĞINLARINDA HABER ARAMAK: İNTERNET GAZETECİİĞİ ÜZERİNE BİR ÇALIŞMA
} ÖZET

Yirmi yılıık kısa geçmişine rağmen, interaktif medya teknolojilerindeki gelişmelerin de etkisi ile internet gazeteciliği önemli dönüşümler geçirmektedir. Geleneksel medya kültürünün ve alışkanlıklarının bir yansıması olarak ortaya çıkan internet gazeteleri, çevrimiçi ortamda kendini yeniden şekillendirmektedir. Ticari kaygılarla şekillendiği görülen internet gazeteciliği, geleneksel düzende gazetecilik adına var olan içerik, format, etik, doğruluk, haber değeri gibi unsurları hiçe sayan uygulama ve işlemlere aracılık etmektedir. Kendi etik kodlarını, rutinlerini yaratmakta oldukça yavaş olan internet gazeteciliğinin -Türkiye örneğinde- önemli sorunlarından biri, "çöp siteler" ve "çöp haberler" dir. Reklam gelirlerinden daha fazla pay almak adına arama motorlarını, internet kullanıcılarını ve reklam verenleri manipüle eden bu tür siteler, kullanıcılara çŏ̆u zaman, "anahtar" olarak nitelendirilen kelime dizinlerinden oluşan, haber değerlerinden uzak içerikler sunmakta ve bu yolla meşru olmayan kazançlar elde etmektedirler. Bu tür internet haber siteleri, kimi zaman henüz açıklanmamış sınav sonuçlarıyla kullanıclları sitesine çekerken kimi zaman da "tuzak başlıklarla" hem bu hizmeti sunan arama motorlarını hem de internet kullanıcısını yanıltmaktadır.

Anahtar Kelimeler: Internet Haberciliği, Arama Motorları, Google News, Çöp Site, Çöp Haber

\section{LOOKING FOR NEWS IN A LOAD OF JUNK: A STUDY ON INTERNET JOURNALISM} ABSTRACT

Despite its short 20-year background, internet journalism has experienced significant transformations due to the effect of developments seen in interactive media technologies. Internet newspapers, appeared as a reflection of traditional media culture and habits, re-shape their format in online media. Internet journalism, which is seen to be shaped by commercial concerns, allows for implementations and operations which disregard journalism factors such as content, format, ethics, accuracy, news value, etc. As seen in Turkey, one of the most important problems of internet journalism, which is so slow in creating its own ethical codes and routines, is "junk websites" and "junk news". The websites, manipulating search engines, internet users, and advertisers for receiving bigger shares from advertisement revenues, present users mostly contents far from news value, comprised by word indexes qualified as "key" and thus, they receive illegal revenues. Such internet news sites sometimes attract users to their websites by undisclosed exam results and sometimes misdirect both serving search engines and internet users by "trap headlines".

Keywords: Internet Journalism, Search Engines, Google News, Junk Site, Junk News 


\section{GIRIŞ (INTRODUCTION)}

1990'lı yıllarla birlikte hayatımıza giren internet, medya ve gazetecilik ortamında önemli değişimler yaşanmasına neden olmuştur. Gazeteciliğin geleneksel tanımlarını ve temel değerlerini yeniden ele almayı zorunlu kılan bu değişimler ardı arkası kesilmeden devam etmektedir. Çevrimiçi haber ortamlarının böylesine değişken bir zeminde yer alması yapılacak araştırmaları da zorlaştırmaktadır. Geleneksel ortamda haberi üretenlerle tüketenler arasında belirgin bir çizgi vardır. Roller, görevler, formatlar açısından bir durağanlık söz konusudur. Ancak çevrimiçi ortamın dinamik, sürekli değişen yapısı içerisinde üretenler ve tüketenler arasına belirgin bir çizgi çizilememektedir. Bu sınırın çizilemeyişinde, internetin zaman ve mekân kavramını dönüştüren interaktif yapısı etkili olmaktadır.

Profesyonel gazetecilik, finansal olarak, teknolojik ve toplumsal boyutları ile dijital devrimin etkisi altındadır. İnsanlar geleneksel yayıncılık alanlarından (tv, radyo) web teknolojisini temel almış dijital yayın mecralarına yönelmektedir. Bu yönelişle birlikte haber ekonomisi, haber medyasının sahip olduğu kitlenin büyüklüğü ve özellikleri ile doğru orantılı hale gelmektedir. Yeni medya ekolojisi, reklamcilara, geleneksel mecraların "rastgele" düzeni yerine "sınıflandırılmış ve sınırlandırılmış" bir düzen sunmakta ve bu durum reklamcıların haber merkezleri üzerindeki etkisini artırmaktadır. Çalışmalar, online ortamda haber editörlerinin ticari kaygılarla hareket ettiklerini ve izleyici ölçüm ve istatistiklerini dikkate alan bir bakış açısı ile içerik oluşturduklarını göstermektedir. Geleneksel haber değeri ilkelerini bir kenara iten ve okuyucuların elektronik ayak izlerini takip eden click-stream (tık akışı) yayıncılık anlayışı, haber toplama ve editöryal karar verme süreçlerinde kamu yararı yerine "tık dostu/popüler" konuların tercih edilmesinin önünü açmaktadır. Ticari kaygılar, haber gündemini şekillendiren gazeteciler üzerinde önemli bir baskı unsuru olmaktadır (Currah, 2009:11-17, 47-49; Dick, 2011:464-465;).

Haberlere yönelik kamu güvenin azaldığı, reklam gelirinin düştüğü ve katılımın, kendi kendini ifade edebilmenin ve dijital medya kültürünün arttığı bir zamanda, gazetecilik, kendi kendini yeniden düşünme ve yeniden icat etme süreci içerisindedir (Deuze, Bruns ve Neuberger, 2007: 322). Bu sürece, çevrimiçi ortamda yayın yapan haber siteleri penceresinden bakıldığında geleneksel etik ve habercilik değerleriyle bağdaşmayan uygulamalara sıklıkla rastlanmaktadır. Geleneksel ortam ve gazetecilik uygulamalarında göremeyeceğiniz türden haber başlıkları, sürekli yinelenip sunulan şiddet, cinsellik/erotizm içeren görseller ve fotoğraf galerileri, reklamla iç içe geçmiş haberlerle yapılan gösterinin tek hedefi ise daha fazla ziyaretçi ve dolayısıla daha fazla gelir elde etmektir.

Geleneksel iletişim araçları açısından yerleşik iş ve pazarlama modelleri mevcut iken çevrimiçi yayın yapan web siteleri, internet gazeteleri henüz bir arayış içerisindedirler. Sitelerin öncelikli hedefi ziyaretçi sayısını artırmak ve ulaşılan tekil ziyaretçi sayısını korumak üzerine yoğunlaşmaktır. Bu süreç içerisinde internette yayın yapan gazeteler özelinde akademik olarak beklenen ise habercilik rutinleri ve değerleriyle bağdaşan, etik kuralları gözeten uygulamalar çerçevesinde bir strateji geliştirmeleridir. Ancak mevcut uygulamalara bakıldığında bunun pek de öyle olmadığı görülmektedir. Internet gazeteleriyle 1995 yılında tanışan Türkiye örnekleminden bakıldığında; habercilik rutinleri ve değerlerini hiçe sayan çok sayıda etik dışı uygulama dikkati çekmektedir. (Işık ve Koz, 2009). Çevrimiçi platformlarda, daha fazla "hit" alarak ticari kayıpların önüne geçme isteği, habercilik açısından etik ihlallerin ortaya 
çıkmasına yol açmaktadır. Artan ticari rekabet, gerçeğe aykırı sansasyonel haberler başta olmak üzere ırkçı, şiddet ve cinsiyet ayrımı yapan haberlerin ve yorumların çevrimiçi ortamlarda kendine yer bulmasına neden olmaktadır. Bu açıdan bakıldığında çevrimiçi ortam etik standartların erozyonuna yol açmaktadır (Ward ve Wasserman, 2010: $285)$.

\section{2. ÇALIŞMANIN ÖNEMI (RESEARCH SIGNIFICANCE)}

Çalışma, ana akım medya karşısında giderek güçlendiği belirtilen internet haber siteleri üzerine odaklanmıştır. Internet gazeteciliğinin önemli sorunlarından biri, "çöp siteler" ve "çöp haberler"dir. Bu tür siteler ve haber içeriklerinin tek amacı, daha fazla "tık" alabilmektir. Cazip reklam flrsatlarından pay alabilmek adına arama motorlarını, internet kullanıcılarını ve reklam verenleri manipüle eden bu tür siteler, kullanıcılara çoğu zaman, "anahtar" olarak nitelendirilen kelime dizinlerinden oluşan, haber değerlerinden uzak ve büyük bir bölümü "kopya" içerikler sunmaktadır. Bu tür internet haber siteleri, kimi zaman henüz açıklanmamış sınav sonuçlarıyla kullanıcıları sitesine çekerken kimi zaman da "tuzak başlıklarla" hem bu hizmeti sunan Google'ı hem de internet kullanıcısını yanıltmaktadır. Çalışmada, profesyonel internet yayıncllarının "yarasalar" olarak nitelendirdiği internet haber sitelerinin, haber değerlerini erozyona uğrattığı varsayılmaktadır. Çalışmanın amacı, bu bakış açısı doğrultusunda, çöp site ve haberleri örnekleriyle ortaya koymak ve bu tür bir haberciliğin altında yatan nedenleri irdelemektir. Çalışma ve sonuçları, henüz emekleme dönemi içerisindeki internet gazeteciliği evreni açısından önemlidir.

\section{3. ÇALIŞMANIN YÖNTEMI (THE METHOD OF THE RESEARCH)}

\section{Çalışma, tarama modeli yöntemini esas almıştır. Literatür} taraması ile birlikte "çöp site" ve "çöp haber" açısından, Türkiye'de yayın yapan internet haber sitelerinden 'örnek olay'lar ele alınacak ve incelenecektir.

\section{4. ÇALIŞMANIN SINIRLILIKLARI (LIMITATIONS OF THE RESEARCH)}

Çalışma, Türkçe dilini kullanan internet siteleri ve "Türkiye'ye özgü internet gazeteciliği" üzerine odaklanmıştır. Çalışma açısından kısıt sayılabilecek bu durum, ileriki çalışmalar için farklı ülkelerdeki örneklerin karşılaştırılması gereğini projeksiyon olarak sunmaktadır.

\section{INTERNET HABER SITELERİNIN GELIR KAYNAKLARI VE ARAMA MOTORLARININ ÖNEMI (REVENUE SOURCES OF NEWS SITES AND THE IMPORTANCE OF SEARCH ENGINE)}

Merkezi bir yapı içerisinde zamanla yarışan internet haber siteleri geleneksel haber kurumlarına oranla maddi açıdan çok daha karmaşık öznelerle rekabet etmektedir. İnternet gazeteleri sürekli değişen, yenilenen bir ortamda bir yandan kullanıcı beklentilerini karşılama ve haberciliğe odaklanma öte yandan finansal/ekonomik olarak ayakta kalma kaygılarıyla yaşamaktadırlar. Başka bir deyişle; geleneksel habercilik değerleriyle ticari çıkarları dengeleme ve sınırları çizilemeyen bir ortamda diğer çevrimiçi aktörlerle rekabet etme uğraşı içerisindedirler (Cohen, 2002:537-538).

Íçerik alanlarını (haber ve arşivlerini) ücretsiz olarak okuyucuya sunan, okuyucu ilgisi ve devamını sağlayacak her türden içeriğe sitesinde yer veren çevrimiçi gazetelerin öncelikli hedefi 
reklam gelirlerini maksimize etmektir. Haberlerin sosyal medya ortamlarında paylaşımı, e-posta bildirimleri, RSS ${ }^{1}$ gibi uygulamalar da ticari hedefleri tutturmaya yönelik işlemlerdir. Reklamcılık, internet gazetelerinin gelirleri açısından baskın kaynaktır ve her geçen gün hızla gelişmektedir. Bu gelişim çevrimiçi gazetelerin ücretsiz içerikler sunmalarını bir bakıma zorunlu hale getirmiştir. Internet gazetelerinde; üyelik zorunluluğu, ücret gibi engellerin kaldırılması ile devasa bir trafik elde edilmiş ve kısa sürede okuyucu sayısı artış göstermiştir. Bu da başlangıç yıllarında denenen ücretli-üyelikli internet gazeteciliği modellerinin sonunu hazırlamıştır (Herbert ve Thurman, 2007:212). Üyelik ve ücretli içerik yöntemi; bu modeli benimsemiş gazeteleri bir çeşit izolasyona sürüklemiş, ortama yabancılaşmalarına neden olmuştur. Hazırlanan içeriğin yalnızca üyelere sunulması; Google, Yahoo, Yandex gibi arama motorları, bloglar ve kullanıcı katılımının had safhada gerçekleştiği sosyal medya ortamlarında paylaşımı engellemek ve önemli trafik kaynaklarını hiçe saymak demektir. Arama motorlarında dizinlenmeyen ücretli içerikler, sadece üyelerin görebildiği haberler, ücretli içerik yöntemini benimsemiş gazeteleri, reklamcllık açısından önemli bir etken olan kullanıcı ve tekil ziyaretçi sayısı açısından gerilere düşürmüş ve bu da internetin en önemli gelir kaynağından mahrum kalmalarına yol açmıştır.

Başlangıç yıllarında internete özgü bir yayın ve işletme modeli geliştiremeyen internet gazeteleri -abonelik yoluyla para kazanma girişimlerinin de başarısızlıkla sonuçlanması ile- gelir elde edebilmenin temel unsurunun "tıklanma sayısı" ile doğru orantılı olduğunun farkına varmışlardır (Işık ve Koz, 2009:169-170). Tirajdan gelir elde edemeyen internet ortamdaki medya organlarının en büyük gelir kaynağını ise reklamlar oluşturmaktadır. İnterneti önemli bir mecra olarak gören reklam verenlerin sayısı giderek artmaktadır. Dünya bazında dijital reklamcılığa ayrılan pay her geçen gün artmakta ve diğer reklam mecralarının önüne geçmektedir. Türkiye'de 2012 yılı dijital reklam harcamalarına bakıldığında en çok yatırımın; "arama motoru reklam yatırımları" üzerine olduğu görülmektedir (444 milyon TL). Ardından display (görüntülenme) reklam yatırımlarına 374 milyon TL'lik bir harcama yapıldığı görülmektedir². Dünya rakamları göz önüne alındığında ise dijital reklam harcamalarının toplam reklam harcamaları içerisindeki payı yüzde 20'lere ulaşmıştır. 2012 yılında dünyada toplam reklam yatırımlarının yaklaşık 500 milyar dolar olduğu ve bu rakamın 100 milyar dolarının dijital ortamlara aktarıldığı bilinmektedir.

$\mathrm{Bu}$ reklam pastasından pay alabilmek için her ne kadar bilinirlik, içerik kalitesi, ziyaretçi sayısı ve profili, görsel kalite gibi unsurlarla ayırt ediciliğinin sağlanması gerekse de bazı internet gazeteleri farklı yollar ve tercihlerde bulunmakta ve siteleri üzerinde sahte bir trafiğin oluşmasına zemin hazırlamaktadırlar. İnternet üzerinde yaratılan sahte trafiklerin, online yayıncılık dünyası açısından sanıldığından daha önemli problemlere yol açacağını ileri süren Paul Barford'a göre, yaratılan bu hileli trafiğin reklamcılar açısından maliyeti -ABD'de- yıllık 180 milyon doları bulmaktadır. Çevrimiçi ortamda yaratılan trafiğin yüzde 35'i insan kaynaklı değildir ve bu bot (internet robotları) yazılımlar

\footnotetext{
1 Rich Site Summary (RSS), genellikle haber să̆layıcıları tarafından kullanılan, yeni eklenen içeriğin kolaylıkla takip edilmesini sağlayan özel bir XML dosya formatıdır. Internet kullanıcısı RSS teknolojisi ile düzenli olarak içerik sunan sitelere abone olabilir ve çeşitli RSS istemcileri sayesinde içeriği takip edebilir.

2 http://www.iabturkiye.org/icerik/2012-dijital-reklam-yatirimlari-30-buyuyerek-1milyar-sinirina-dayandi, Erişim Tarihi: 18 Aralık 2013
} 
sayesinde gerçekleştirilmektedir. (Sebastian, 2013). "Sahte içerikler" ve hileli yöntemler ile yapılan bu uygulamalar alışılagelmiş gazetecilik değerlerini ve etik ilkeleri hiçe sayarken, reklam verenler açısından da büyük bir soruna yol açmaktadır. Çevrimiçi ortamda yaratılan sahte trafikler reklam verenlerin yatırımlarının önemli bir bölümünün boşa gitmesi anlamına gelmektedir. Özellikle gösterim başı ücretlendirilen reklamlardan, sahte içerik üreticisi internet sitelerinin faydalanması; oyunu kuralına uygun oynayan internet haber siteleri, arama motorları ve reklam verenler açısından önemli bir soruna işaret etmektedir.

\section{6. İNTERNET GAZETECİLİ̆̇̇ AÇISINDAN ARAMA MOTORLARININ ÖNEMI (THE IMPORTANCE OF SEARCH ENGINES IN TERMS OF ONLINE JOURNALISM)}

Arama motorlarının çevrimiçi yayın yapan haber siteleri ve reklamcılık açısından önemini kavrayabilmek için öncelikle bu ortamda "arama mantığının" nasıl işlediğini anlamak gerekmektedir. Google Kalite Grubu mühendisi Matt Cutts, -Google özelinde- arama mantığını şöyle anlatmaktadır (2010):

"... Öncelikle, Google'da bir arama yaptığınızda, aslında Web' de değil Google'ın web dizininde (en azından bulabildiğimiz kadarında) arama yaptığınızı bilmenizi isterim. Bu işlemi "Örümcek" adı verilen yazılım programlarıyla yapıyoruz. Örümcekler ilk olarak birkaç Web sayfası getirir, ardından bu sayfalardaki bağlantıları izleyerek bunların gösterdiği sayfaları getirir ve sonra bu sayfalardaki bağlantıları izler. Süreç ağda binlerce makine üzerinde milyarlarca sayfa dizine eklenene kadar devam eder. Şimdi diyelim ki, bir çitanın ne kadar hızlı koştuğunu öğrenmek istiyorum. "Çitanın koşma hızı" diye aramamı yazar ve enter tuşuna basarım. Yazılımımız bu arama terimlerini içeren her bir sayfayı bulmak için dizinimizi arar. Bu örnekte, yüzbinlerce olası sonuç vardır. Google gerçekte istediğim birkaç sayfanın hangileri olduğuna nasıl karar verir? Sorular sorarak. 200'den fazla soru vardır. Örneğin arama terimlerimiz bu sayfada kaç kez geçiyor? Kelimeler başlıkta mı, URL'de mi, terimler yan yana mı? Sayfada bu kelimelerin eş anlamlıları bulunuyor mu? Bu sayfa kaliteli bir web sitesinden mi yoksa düşük kaliteli, hatta spam gönderen bir siteden mi? Sayfanın Page Rank'ı nedir? Son olarak, tüm bu etkenleri birleştirerek her sayfanın genel puanını belirleriz ve aramanızı göndermenizden sonra yaklaşık yarım saniye içinde arama sonuçlarınızı karşınızı getiririz. Google'da, kullanışlı ve tarafsız arama sonuçları sunma taahhüdümüz çok ciddiye alırız. Hiçbir zaman sitenizi dizinimize eklemek, daha sık güncellemek ve sıralamasını yukarı çekmek için para almayız. Şimdi benim arama sonuçlarıma bakalım. Her girişte hangi sayfanın aradığım sayfa olduğuna karar vermeme yardımcı olacak bir başlık, bir URL bir metin pasajı bulunuyor. Ayrıca benzer sayfalara bağlantılar, sayfanın Google tarafından saklanan en son sürümü ve bir sonra denemek isteyebileceğim alakalı aramaları da görüyorum. Bazen de sağda ve üstte reklamlar görüyorum. Reklamcılık işimizi de çok ciddiye alıyoruz ve hem reklam verenlere mümkün olan en iyi kitleye reklam sunma taahhüdümüzü yerine getirmek hem de sizlere yalnızca gerçekten görmek isteyebileceğiniz reklamlar göstermek için elimizden geleni yapıyoruz. Reklamlarınızı normal arama sonuçlarından ayırmaya büyük özen gösteriyoruz ve aradığınız bilgiyi bulmanıza yardımcı olacağına inandığımız reklam bulamazsak hiç reklam göstermiyoruz." 
Yukarıdaki açıklamalardan da anlaşılacağı üzere arama motoru üzerinde yapılan bir aramada ilgili anahtar kelimenin geçtiği siteler, teknolojik bir yazılım (örümcekler) sayesinde yarım saniye içerisinde taranmakta ve sonuçlar ziyaretçinin karşısına çıkarılmaktadır. Arama yazılımları açısından dikkate alınan konulara bakıldığında; ilgili anahtar kelimenin o sitede kaç kez geçtiği, başlıkta mı, URL'de mi yer aldığı, sitenin page rank değeri vb. çok sayıda değerlendirme kıstası bulunduğu görülmektedir. Söz konusu değerlendirme kriterleri ile birlikte arama trendlerini yakından takip eden çöp siteler de içeriklerini bu iki temel noktayı dikkate alarak oluşturmakta ve arama motorlarının kullanıcılarını "avlamaya" çalışmaktadırlar.

Haberin zamanla olan yarışı hayatımıza 1998 yılında giren Google tarafından 11 Eylül 2001'de ABD'yi sarsan saldırılar sonrası bir kez daha anlaşılmıştır. Google, 11 Eylül saldırıları sonrası, saldırılarla ilgili arama oranlarındaki artış üzerine Google News'i uygulamaya sokmuştur. Bugün Google News, 39 dilde yayın yapmakta ve milyonlarca kişiye, çeşitli haber kaynaklarından güncel haberler sunmaktadır. Google'ın bu hizmeti bugün özellikle telif hakları ihlalleri nedeniyle birçok ülkede tartışma konusu haline gelmiştir. Google, "internetin paraziti" olarak tanımlayan hatta onu "dijital vampir" olarak nitelendiren bazı medya kuruluşları, haber hizmetinin sonlandırılması için ciddi düzeyde mücadelelerini sürdürmektedir. Birçok Avrupa ülkesinde Google'ın izinsiz haber içeriği kullanımına yönelik davalar açılmış ve Google telif ödemeye mahkûm edilmiştir.

Öte yandan Google, tüm bu eleştiri ve cezalara rağmen yayıncı kuruluşlar için önemli bir gelir kaynağıdır. "AdSense" ile kendi reklam platformunu kuran Google, bugün milyonlarca yayıncı için Türkiye gibi ülkelerde "vergisiz" önemli bir gelir kaynağı haline gelmiştir. Google, AdSense ile geçtiğimiz yıl, dünya genelindeki yayıncılara 6,5 milyar dolar ödeme yapmıştır. Her yıl katlandığı belirtilen bu rakamlar, birçok yayıncının da iştahını kabartmaktadır.

Haber sitelerinin, arama motorlarında daha üst sıralara çıkarak, daha fazla ziyaretçi trafiği elde etme yarışı, Google News ile birlikte daha da kızışmıştır. Google News, kısaca Krishna Bharat'ın 11 Eylül saldırılarıyla ilgili arama eğilimini dikkate alarak inşa ettiği, bir tür haber sistemidir. Google News, bugün 30 ayrı dilde 72 farklı sürümde yaklaşık 5 bine yakın Türkiye' de ise 200 civarı haber kaynağından içerik derlemektedir. Google News'in ana fikri farklı haber kaynaklarından, benzer haber içeriklerini derleyerek, tek bir sayfada okuyucuya sunmaktır. Google News'te yer alacak siteler, Google tarafından belirlenir ve kuralları ihlal ettiği düşünülen siteler, aramalardan çıkarılır.

Habere öykülerinde yer alan ve sıklıkla geçen "anahtar kelimelerden" yola çıkan Google News, mevcut sıralamanın aksine, yeni bir sıralama oluşturur. Bu sistem aynı zamanda Google algoritmasının, kısmen de olsa manipüle edilmesini sağlamıştır. Organik aramalarda, hatırı sayılır bir sıra elde edemeyen yayıncılar, Google News'i manipüle ederek, milyonlarla ifade edilen bir trafik elde etmektedir. Sistemi manipüle ederek, daha fazla trafik elde etme isteği Yahoo'nun Trustrank ${ }^{3}$ ölçüsünü ortaya koyarken işaret ettiği "spam" sitelerinin benzeri "çöp haber sitelerin" oluşmasına neden olmuştur.

\footnotetext{
3 TrustRank, Stanford Üniversitesi ve Yahoo tarafından tanımlanan ve spam sitelere mücadelede kullanllan bir link analiz tekniğidir. Ticari nedenlerle arama motoru sonuçlarında yükselmek isteyen ve bunun için spam tekniklerini kullanan web sitelerini önlemek için kullanılan bir sistemdir.
} 


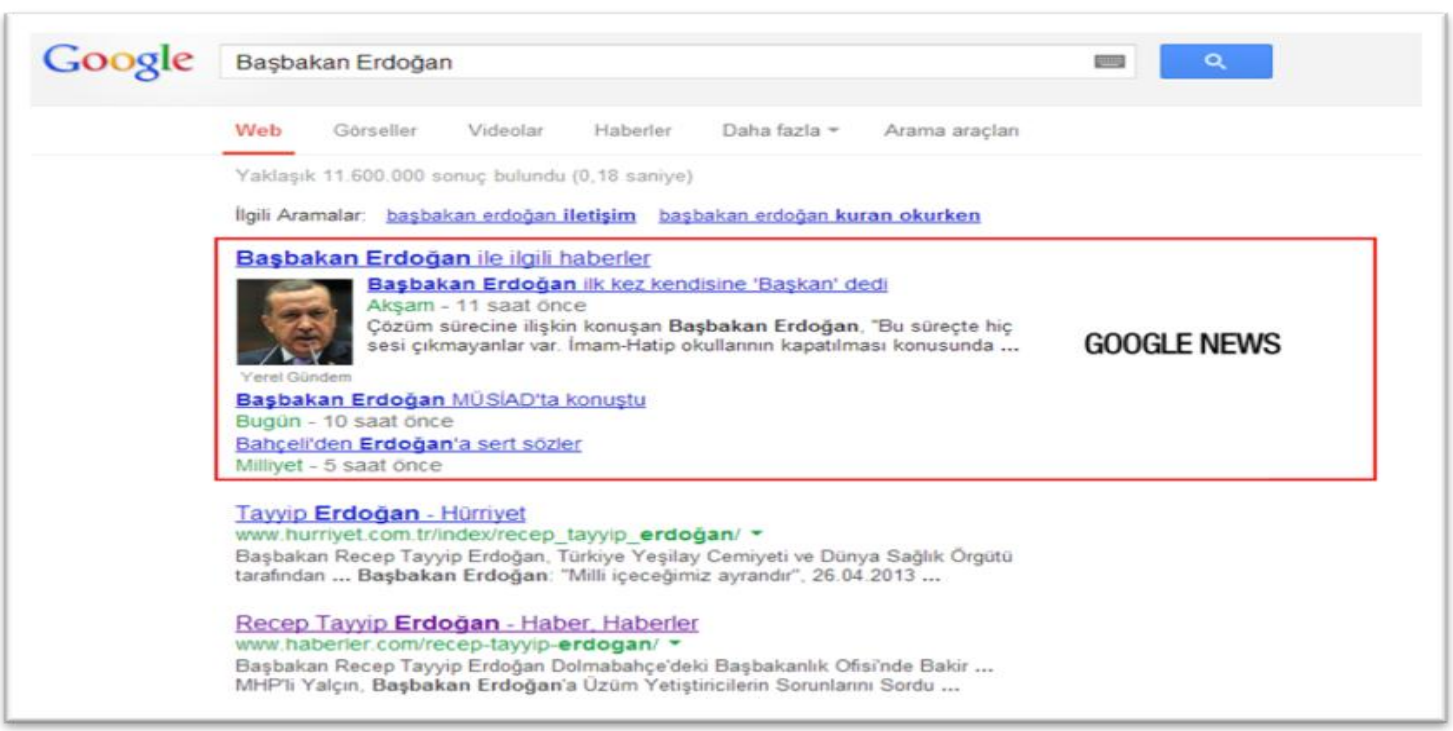

Şekil 1. Google news bölümü

(Figure 1. Google news section)

Google, "Başbakan Erdoğan" ile ilgili aramada, yukarıda da görüldüğü gibi "Başbakan Erdoğan ile ilgili haberler" başlığıyla, haber sitelerindeki haberleri, ayrı bir başlık altında toplamıştır. Akşam, Bugün ve Milliyet gazeteleri, organik aramalarda sıralamada bile yer almazken, Google News sayesinde Hürriyet ve haberler.com sitelerinin önüne geçmiştir.

Google, Yahoo, Yandex vb. arama motorları internet gazeteleri için birincil öneme sahip okuyucu-trafik kaynakları olarak işlev görmektedir. Ülkemiz ve dünya ölçeğinde arama motorları en çok ziyaret edilen sitelerin başında gelmektedir. Web ağı üzerinde yer alan siteleri ve içeriklerini endeksleyerek, ziyaretçi aramalarındaki anahtar kelimelere göre bir siralama sunan arama motorları, ziyaretçilerin diğer sitelere ulaşmalarını sağlayan bir kavşak noktası olarak işlev görmektedir. İnternet haber sitelerinin trafik kaynakları açısından da arama motorları son derece önemlidir.

Google Analytics, Statcounter ve Awstats gibi web trafiği istatistik ve analiz programları, web siteleriyle ilgili, site yöneticileri ve reklam verenlere; ziyaretçi sayısı, trafik kaynakları ve kullanım süreleri gibi parametreler sunmaktadır. Google Analytics'te trafik kaynakları; (1) doğrudan trafik, (2) organik trafik, (3) yönlendirme siteleri ve (4) sosyal medya araçları başlıkları altında sıralanmaktadır. "Doğrudan trafik", kullanıcının adres çubuğuna, sitenin ismini yazarak ulaştığı trafik olarak tanımlanırken, farklı internet adreslerindeki linkler aracılığıyla sağlanan trafik ise "yönlendirme siteleri" parametresi altında yer almaktadır. "Organik trafik" ise arama motorlarından "anahtar kelime" arayarak gelen ziyaretçilere işaret etmektedir. Facebook, Twitter gibi sitelerde paylaşılan linkler aracılığıyla gelen ziyaretçiler ise "sosyal medya" başlığı altındadır.

Arama motorlarının, internet haber siteleri için neden hayati öneme sahip olduğunu görebilmek için ankarahaber.com adlı sitenin 1 Eylül-31 Ekim 2012 tarihleri arasındaki Google Analytics verilerine bakmak yeterli olacaktır: 


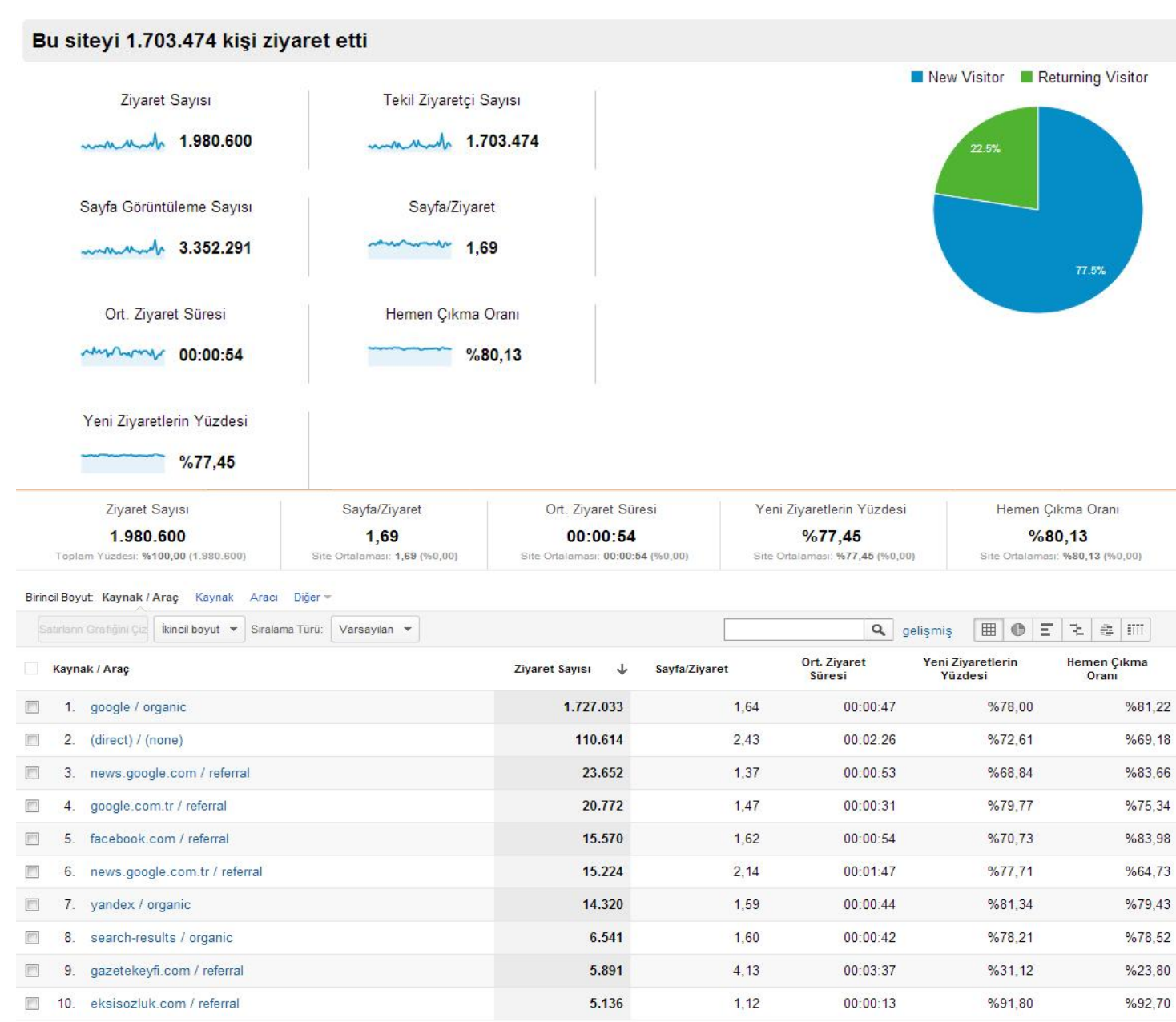

Şekil 2. Ziyaretçi sayısının trafik kaynaklarına göre dağılımı

(ankarahaber.com, 1 Eylül-31 Ekim 2012)

(Figure 2. The distribution of the number of visitors to the traffic sources (ankarahaber.com, 1 September to 31 October 2012))

Ankarahaber.com sitesinin kullanıcı verileri incelendiğinde, ziyaretçi trafiğinin büyük bir bölümünün "arama motorlarından" sağlandığı görülmektedir. Organik trafiğe ilişkin yapılan ayrıntılı anahtar kelime analizinde ise ziyaretçilerin 394 bininin "Ankara Haber" anahtar kelimesine ilişkin sorgu sonunda siteye ulaştığı görülmüştür. Sitenin bilinirlik oranının yansıttığı düşünülen bu arama, doğrudan trafik içerisinde kabul edilmektedir. Bu değerlendirmeyle birlikte, sitedeki organik arama trafiği, yani arama motorlarından çeşitli anahtar kelimeler kullanarak gelen ziyaretçi sayısı 1 Milyon 386 bin civarıdır. Buradan hareketle yapılan bir değerlendirmede sitenin toplam trafiğinin yaklaşık yüzde 70'lik bir bölümünün organik aramalardan geldiği, bir başka deyişle ziyaretçilerin yüzde 70'inin "arama motoru" kaynaklı olduğu görülmektedir.

Arama motorları, çevrimiçi ortamda yayın yapan her tür siteye ziyaretçi yönlendirmektedir. Arama motorları, geleneksel anlamda temsili olan, belli bir okuyucu kitlesine sahip gazetelerin internet siteleri için de aynı derece de önemlidir. Dünya genelinde siteler için istatistikler sunan alexa.com'un verileri incelendiğinde; Türkiye'nin en çok ziyaret 100 sitesi içerisinde yer alan, 
milliyet.com.tr'nin (6' 1 ncl) yüzde 18.53'nün, hurriyet.com.tr'nin (9'uncu) yüzde 20,92'sinin, ensonhaber.com'un (15'inci) yüzde 21,57'sinin, haberler.com sitesinin (32'inci) yüzde 40,17'sinin arama motorlarından geldiği görülmektedir.

Tablo 1. Hürriyet, Milliyet ve ensonhaber.com haber sitelerinin trafik kaynakları (alexa.com)

(Table 1. Traffic sources: Hürriyet, Milliyet and ensonhaber.com (alexa.com))

\begin{tabular}{|c|c|c|c|c|c|}
\hline \multicolumn{2}{|c|}{ hurriyet.com.tr } & \multicolumn{2}{|c|}{ milliyet.com.tr } & \multicolumn{2}{|c|}{ ensonhaber.com.tr } \\
\hline \%o of Unique Visits 0 & Upstream Site & \% of Unique Visits 0 & Upstream Site & \% of Unique Visits 0 & Upstream Site \\
\hline $14.19 \%$ & google.com.tr & $14.05 \%$ & google.com.tr & $17.14 \%$ & google.com.tr \\
\hline $9.42 \%$ & facebook.com & $8.87 \%$ & facebook.com & $11.61 \%$ & facebook.com \\
\hline $5.47 \%$ | & google.com & $6.43 \%$ & milliyet.tiv & $4.43 \%$ I & google.com \\
\hline $3.65 \% \quad 1$ & milliyet.com.tr & $4.91 \%$ I & skorertiv & $2.63 \% \quad \mid$ & kadinvekadin.net \\
\hline $2.26 \% \quad \mid$ & twitter.com & $4.49 \% \quad$ I & hurriyet.com.tr & $2.59 \% \quad \mid$ & youtube.com \\
\hline $2.01 \% \quad \mid$ & youtube.com & $4.48 \% \quad$ I & google.com & $1.96 \%$ & haberturk.com \\
\hline $1.77 \%$ & haberturk.com & $2.11 \% \quad \mid$ & youtube.com & $1.92 \%$ & twitter.com \\
\hline $1.60 \%$ & hurpass.com & $1.76 \%$ & vatanim. com.tr & $1.79 \%$ & hurriyet.com.tr \\
\hline $1.26 \%$ & googlede & $1.51 \%$ & twitter.com & $1.69 \%$ & milliyetcom.tr \\
\hline $1.23 \%$ & live.com & $1.36 \%$ & haberturk.com & $1.25 \%$ & haber7.com \\
\hline
\end{tabular}

Yukarıdaki verilerin ışığında, okuyucularına online haber sunan bu web sitelerinin de, en önemli trafik kaynağının, "arama motorları" olduğu görülmektedir. Arama motorları aracılığıyla gelen ziyaretçi sayısındaki bu oranlar, SEO (Search Engine Optimization) çalışmalarının daha da önem kazanmasına neden olmuştur. "Arama Motoru Optimizasyonu" olarak nitelendirilen SEO, sitelerin kapsam ve içeriklerine uygun olarak hedefledikleri anahtar kelimelerde, arama motorlarının sonuç sayfalarında, üst sıralarda çıkması için yapılan "bilinirlik" çalışmalarını kapsamaktadır (Goldsborough, 2011: 13). Çöp siteler açısından optimizasyonun anlamı ise sitenin kapsam ve içeriğine bakılmaksızın, "daha fazla ziyaretçi ve daha fazla reklam geliri elde etme" üzerine yoğunlaşmaktır.

Alexa verilerine göre Türkiye'de en çok ziyaret edilen site Google'dır. Türk kullanıcılar, haber öykülerine de yine büyük oranda Google aracılığıyla ulaşmaktadır. Google AdWords'ün Nisan 2013 tarihli arama trafiği raporuna göre; yerel aylık aramalarda "haber" kelimesi 68 milyon kez aranmıştır. Google AdWords verilerine göre Türkiye'deki aramalarda; "haberler" kelimesi 37 milyon, "son dakika" kelimesi ise 9 milyon kez aranmıştır. Sadece bu veriler dikkate alınarak yapılacak bir değerlendirmede, Türk kullanıcıların bu üç kelimeye ilişkin, aylık 114 milyon 340 bin günlük ise 3,8 milyonluk bir arama yaptığı görülmektedir. Google'da; haber, haberler ve son dakika anahtar kelimeleri kullanılarak yapılan aramalarda ilk beş sırada görülen haber siteleri ise şu şekildedir (14 Mart 2013 itibarıyla); 
Tablo 2. "Haber" ve "son dakika" aramalarında ilk 5 site (Table 2. The first five sites in searching: "news" and "last minute")

\begin{tabular}{|l|l|l|l|}
\hline Sıra & Haber & Haberler & Son Dakika \\
\hline 1. & hurriyet.com.tr & haberler.com & sondakika.com \\
\hline 2. & haberler.com & hurriyet.com.tr & haberturk.com \\
\hline 3. & ensonhaber.com & ensonhaber.com & haber7.com \\
\hline 4. & haber7.com & haber7.com & internethaber.com \\
\hline 5. & internethaber.com & mynet.com & haberler.com \\
\hline
\end{tabular}

İlgili üç anahtar kelime ve aramalardaki sıralamaları dikkate alındığında; Google üzerinden gerçekleşen günlük 3,8 milyonluk aramanın, büyük bir oranının bu 5 site arasında paylaşıldığı görülmektedir. Üst sıralarda yer alan anahtar kelimeler arttıkça, bu rakamlarda artmakta, bu da o siteler için reklam gelirlerinin artması anlamına gelmektedir. Adı geçen sitelerin Alexa verilerine göre "haber" kelimesinin, organik aramalardaki tıklanma oranları ise; www.hurriyet.com.tr (yüzde 9.56), haberler.com.tr (yüzde 1.50), ensonhaber.com (yüzde 3.49), haber7.com.tr (yüzde 2.48) ve internethaber.com.tr (yüzde 2.30) olarak gerçekleşmiştir.

İgili listede haberler.com'un verileri hariç, diğer 4 sitede görüldüğü gibi haber kelimesine ilişkin yapılan aramada, sitenin sıralaması ile o kelimeden gelen trafik doğru orantılıdır. Özetle, Google'da, anahtar kelime aramalarında sitelerin sıralamaları geriledikçe, o anahtar kelimeden gelen ziyaretçi oranları azalmaktadır.

\section{7. "ÇÖP" SİTELER VE "ÇÖP" HABERLER ("JUNK SITES" AND "JUNK NEWS")}

Çalışmanın konusunu oluşturan, adına "spam" ya da "çöp" site diyebileceğimiz çok sayıda web sitesi de arama motorlarındaki mevcut mantığın farkına varmıştır. Bu siteler yarattıkları sözde içeriklerle; internet kullanıclarını, reklam verenleri ve arama motorlarını manipüle etmektedir.

Çöp site ve haberlerde içerik ikinci plandadır. Google'daki arama trendleri takip edilerek oluşturulan sayfalardaki asıl amaç ise ne pahasına olursa olsun başlığın tıklanmasının sağlamak ve ziyaretçiyi sayfaya çekmektir. Söz konusu çöp siteler günlük, aylık düzeyde gündemde olan, hatta henüz gerçekleşmemiş konu ve durumları dikkate alan bir strateji ile içeriklerini oluşturmaktadırlar. Henüz açıklanmamış sınav sonuçları, yayınlanmamış dizi fragmanlarını konu alan haberler rahatlıkla bu tip sitelerde kendine yer bulabilmektedir. Künyesiz yüzlerce internet haber sitesinin sıklıkla başvurduğu bu yöntem, internet haberciliğine olan güvenin azalmasına ve yayıncılık kalitesinin düşmesine neden olmaktadır.

Geleneksel medya organlarının da benzer uygulama ve yöntemlere başvurduğu aşikârdır. Belirli bir kurum kültüründen gelen geleneksel medya temsilcilerinin, çevrimdışı ortamda sahip olduğu etik değer ve ilkelere çevrimiçi ortamda kayıtsız kaldıkları ve "çöp" haberlere sayfalarında yer verdikleri görülmektedir. Aşağıda söz konusu uygulamalardan örnekler ayrıntılarıyla ele alınacaktır.

Milliyet.com.tr'de 25 Nisan 2013 tarihli "Kurtlar Vadisi Pusu" dizisine ilişkin haber, "Kurtlar Vadisi Pusu 190. Son Bölümde Heyecan Doruktaydı" başlığıyla sunulmuştur. Milliyet, bu başlıkla "Kurtlar Vadisi Pusu" kelimesindeki aramalarda Google News'in ilk sırasında yer almıştır. Haber incelendiğinde, başlığın arama motorlarına uygun olarak anahtar kelimelerden oluşturulduğu, içeriğin gazetecilik 


\begin{tabular}{|c|c|c|c|c|c|c|c|c|c|c|c|}
\hline \multirow{2}{*}{\multicolumn{4}{|c|}{$\begin{array}{l}\text { değerleri açısından } \\
\text { görülmektedir. } \\
\end{array}$}} & zayif & ve & ec & itöryal & \multicolumn{2}{|c|}{ hatalarla } & dolu & olduğ \\
\hline & & & & \multicolumn{4}{|c|}{ Magazin } & \multicolumn{3}{|c|}{ Kelime ya da Haber } & \\
\hline Ana segfa & Son Dakcas & Gundam & Exonoml & Finans & EKOTEET & Dunya & syasot Mag & azin Yazariar & Galan & (1) unget.tv & Tumo- \\
\hline \multicolumn{8}{|c|}{ 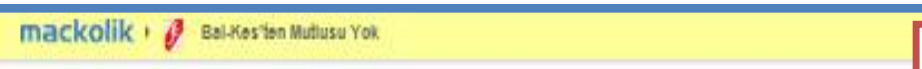 } & \multirow{3}{*}{\multicolumn{4}{|c|}{$\begin{array}{l}\text { Haberin spotunda anahtar } \\
\text { kelimeler sürekli tekrar } \\
\text { edilmistir. Anahtar } \\
\text { kelimeler arama } \\
\text { motorlarını manipüle } \\
\text { etmek için ardarda } \\
\text { sıralanmiştır. }\end{array}$}} \\
\hline \multicolumn{8}{|c|}{$\begin{array}{l}\text { Kurtlar Vadisi Pusu 190. Son Bölümde } \\
\text { Heyecan Doruktaydı }\end{array}$} & & & & \\
\hline \multicolumn{8}{|c|}{$\begin{array}{l}\text { Kurtlar Vadisi Pusu 190. son bölüm } 25 \text { Nisan } 2013 \text { Kurtlar vadisi pusu } 190 . \\
\text { son bölüm } 25 \text { nisan } 2013 \text { perşembe kvp son bölüm }\end{array}$} & & & & \\
\hline
\end{tabular}

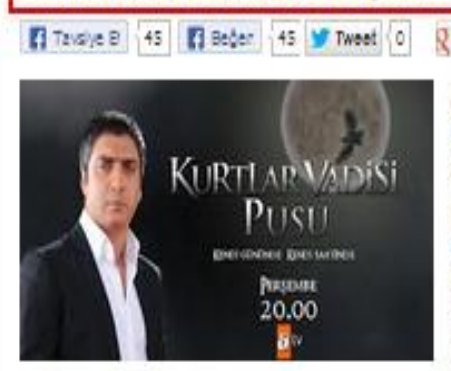

Aksjyon ve gerilimin odak noktası haline gelen Kurtlar Vadisi Pusu son bölümde heyecan yine doruktaydi. Kurtlar vadisi pusu uzun yillar geçmesine rağmen halen en pok izlenen ve internet te de en çok aranan ve tiklanan diziler arasinda yer almaya devam ediyor. 10 Yallk bir süredir ekranlann tutkusu ve vazgeçilemeyen dizisi kurtlar vadisi pusu lik olarak show tv de seyircisiyle buluş̧u ve daha sonra karal D, star, atv, TNT ve son olarak yine atv ekranlanna dönen dizi macerasına son sürat devam ediyor. Ele aldiğ devlet, derin devlet, mafya dş gügler , siyasi gibi olaylan konu edinen kurtlar vadisi pusu Tüm Türkiye de merak uyandird.

Kurtlar vadisi pusu yeni bölümleri ile her hafta kurtlar vadisi gününde ve saatinde ekranlara geliyor. Kurtlar vadisi pusu yeni 190. Yeni bölüm fragman online sitemizde bulabilirsiniz. Her gẹen bölumi kạ̣nimaz bir tutku haline gelen kurtlar vadisi yeni bölüm de nefesler yine kesilecek gibi...

Türk televizuonlannin rekortmen dizisi kurtlar vadisi pusu yeni bölümleri online sitemizde haberaj.com da. Kurtlar vadisi pusu 190. yeni bölüm fragmani yayniandi. Ekranlann worgecilemeyer dizisi kurtlar vadisi pusu son bölümde, dizi severler yine unutulmayacak müthis sahnelere tankklk etti. Aksiyon dizilerinin rekortmen dizisi kurtlar vadisi pusu her hafta en p̧ok izlenenler arasinda... dizi severler, kurtlar vadisi pusu yu Perşembe akşam dizi bittikten sonra bir sonraki haftayı ,yani yeni bölümlerini adeta iple cakiyor. Türkiye nin fenomen dizisi

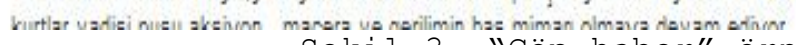

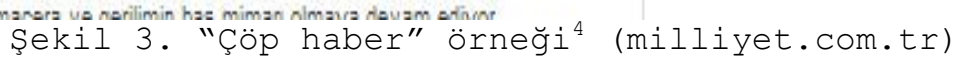
(Eigure 3. Example of "junk news" (milliyet.com.tr))

\footnotetext{
4 http://magazin.milliyet.com.tr/atv-canli-izle-kurtlar-vadisi-pusu-190-yeni-bolum-atvden-canli-izle-25-nisan-2013persembe/magazin/magazindetay/25.04.2013/1698623/default.htm, Erişim: 29 Nisan 2013.
} 
Bir başka örnek, arama motorunda Spor Toto Süper Lig'in 31'inci haftasında, Gaziantep- Galatasaray maçına ilişkin, Google'da "Gaziantep Galatasaray maçı" aramalarında, sonuçlar aşağıdaki şekilde sıralanmaktadır.

\section{Google galatasaray gaziantep maçı Web Görseller Videolar Haberler Daha fazla - Arama araçlanı \\ Yaklașıı 18.000 .000 sonuç bulundu $(0,16$ saniye $)$

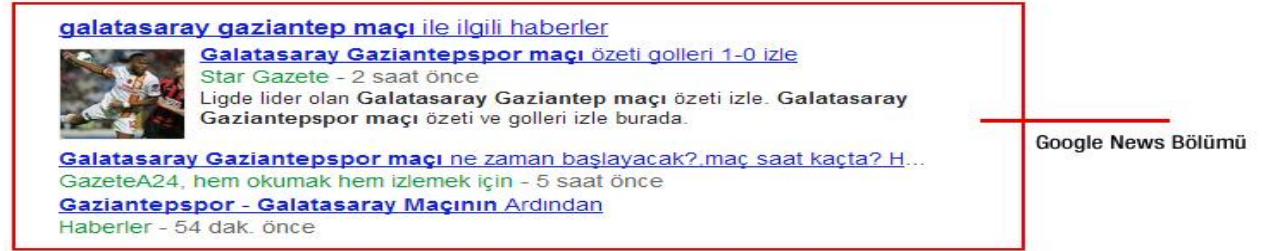 Haberler -54 dak. önce

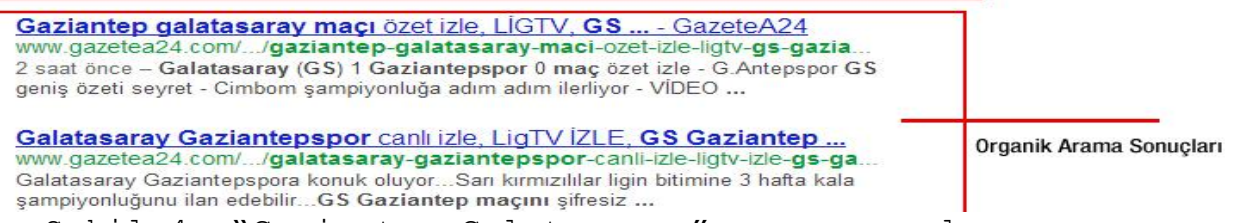 Giyonluğunu ilan edebilir...GS Gaziantep maçını şifresiz \\ Şekil 4. "Gaziantep-Galatasaray" maçı aramaları \\ (Figure 4. "Gaziantep Galatasaray" match searches)}

Sonuç sayfasında, GazeteA24.com sitesinin hem organik aramalarda hem de Google News aramalarında yer aldığı görülmektedir. Alexa'nın Türkiye sıralamasında, site 164. sırada yer almaktadır ve toplam ziyaretçinin yüzde 60'a yakın bölümü arama motorlarından gelmektedir.

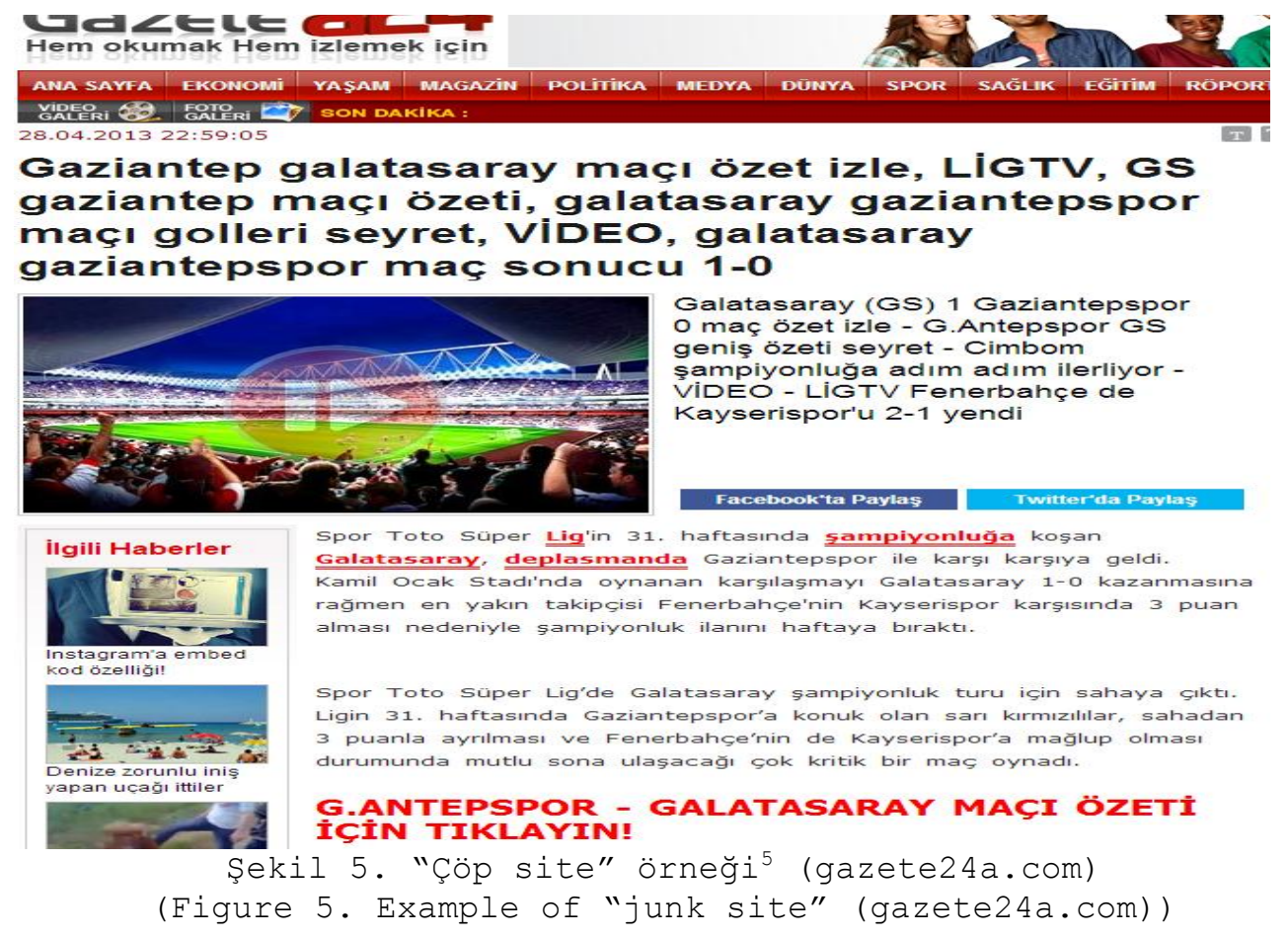

\footnotetext{
${ }^{5}$ http: //www.gazetea24.com/haber/gaziantep-galatasaray-maci-ozet-izle-ligtv-gs-gaziantepmaci-ozeti-galatasaray-gaziantepspor-maci-golleri-seyret-video-galatasaraygaziantepspor-mac-sonucu-1-0_23421107.html, (Erişim: 30 Nisan 2013)
} 
28 Nisan 2013 tarihinde oynanan "Gaziantep Galatasaray maçı", şifreli olan Lig TV'de yayınlanmıştır. Maça ilişkin her hangi bir görüntünün, ilgili internet sitelerinde, telif hakları nedeniyle yer alması mümkün değildir. Buna rağmen, üç arama sonucundan ikisinde çıkan Gazetea24.com adlı sitenin, haber başlıklarında "maç özet izle", "canlı izle" anahtar kelimelerini kullandığı görülmektedir. Bu başlıklar tıklandığında ise karşılaşmaya ilişkin herhangi bir videonun olmadığı görülmektedir. Haberin detayında yer alan video ise Galatasaray- Real Madrid karşılaşmasına ait görüntülerdir.

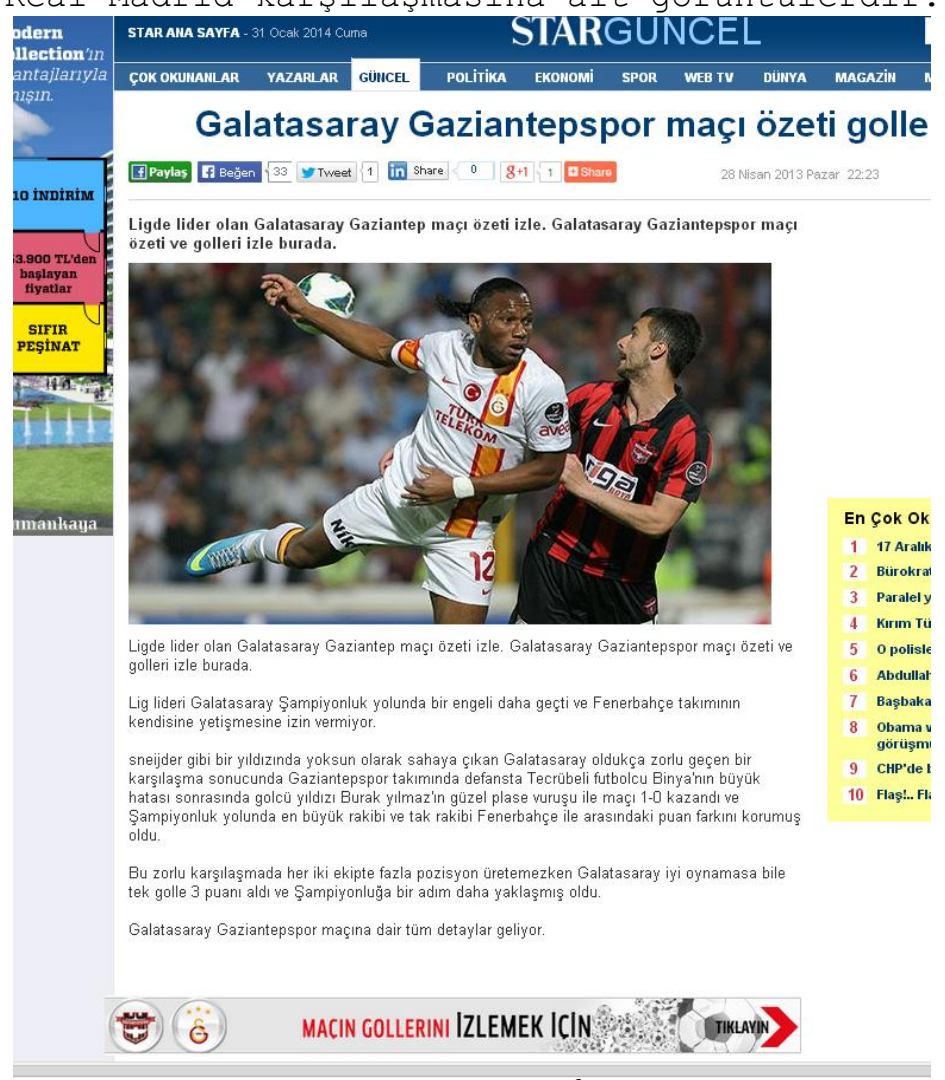

Şekil 6. "Çöp haber" örneğí (stargazete.com)

(Figure 6. Example of "junk news" (stargazete.com))

Benzer başlık hilesi Star Gazetesi'nin resmi web sitesi olan ve Google News bölümünün ilk sırasında yer alan stargazete.com'da da yapılmıştır. Gazete, "Galatasaray Gaziantep maçı özet golleri 1-0 izle" başlığıyla sunduğu haberinde, "izle" kelimesini kullanarak okuyucuyu yönlendirmekte; ancak içerikte herhangi bir video yer almamaktadır.

Google News'in "Galatasaray Gaziantep maçı ile ilgili haberler" kategorisi tıklandığında ise çok sayıda hileli başlıkların bulunduğu görülmüştür. Google'un 140 farklı kaynaktan derlendiğini söylediği haberler sıralanırken, yine okuyucuyu kandırmaya yönelik haber başlıklarının çoğunlukta olduğu, sistemin çöp siteler tarafından işgal edildiği görülmektedir. Sonuç sayfasında yer alan başlıklar ve yayıncıları aşă̆ıdaki tabloda yer almaktadır.

\footnotetext{
${ }^{6}$ http://haber.stargazete.com/guncel/galatasaray-gaziantepspor-maci-ozeti-golleri-10izle/haber-749439, (Erişim, 30 Nisan 2013)
} 
Tablo 3. Google News'te "Gaziantep Galatasaray" maçı aramaları

(Table 3. "Gaziantep Galatasaray" match searches in Google News)

\begin{tabular}{|c|c|}
\hline stargazete.com & Galatasaray Gaziantepspor maçı hangi kanalda ne zaman \\
\hline gazetea24.com & $\begin{array}{llll}\text { Galatasaray } & \text { Gaziantepspor } & \text { maçı } & \text { ne } \\
\text { başlayacak?,maç saat... } & & & \end{array}$ \\
\hline samanyoluhaber.com & Gaziantepspor Galatasaray maçı özeti (0-1)- \\
\hline habergazete.com & $\begin{array}{l}\text { Galatasaray Gaziantep maçı saat kaçta hangi kanalda } \\
\text { yayınlanacak }\end{array}$ \\
\hline beyazgazete.com & $\begin{array}{l}\text { Gaziantepspor Galatasaray Maçı Ne Zaman Saat Kaçta? } \\
\text { İle }\end{array}$ \\
\hline spothaber.com & $\begin{array}{l}\text { Galatasaray Gaziantepspor maçı ne zaman saat kaçta? GS } \\
\text { Antep ne zaman }\end{array}$ \\
\hline habergazete.com & $\begin{array}{lccccc}\text { Galatasaray Gaziantep maçı } & \text { SONUCU ÖZET } & 1-0 & \text { Gs- } \\
\text { G.Antepspor maçı GENIŞ ÖZETI- } & & & & \end{array}$ \\
\hline e-haberajansı.com & GS - G.Antepspor maçı özet ve golleri burada olacak \\
\hline rotahaber.com & Galatasaray Gaziantep 0-0 maçı canlı Lig tv'de izle \\
\hline haber01.com & $\begin{array}{l}\text { Galatasaray Gaziantepspor Maçı Özeti ve Golleri İzle } \\
\text { (GS ŞAMPIYO) }\end{array}$ \\
\hline kirikhan.net & Gaziantepspor Galatasaray maçı canlı izle Lig TV'de \\
\hline netgazete.com & $\begin{array}{l}\text { Gaziantepspor Galatasaray maçı - Canlı Lig } \\
\text { izle'yebilirsiniz ... }\end{array}$ \\
\hline haberfx.com & $\begin{array}{l}\text { Gaziantep 0-1 Galatasaray Maç Özeti İzle (Gaziantep 0- } \\
1 \text { GS Maçı ... }\end{array}$ \\
\hline haberaktuel.com & $\begin{array}{l}\text { Gaziantep Galatasaray maçı özeti / Süper Lig puan } \\
\text { durumu- }\end{array}$ \\
\hline
\end{tabular}

Google

Web Görseller Videolar Haberler Daha fazla - Arama araçlan

Yaklaşik 105.000 sonuç bulundu $(0,12$ saniye $)$

Galatasaray Gaziantepspor maçı özeti golleri 1-0 izle

Star Gazere-3 sast ondo

作

karģlaşma sonucunda Gaziantepspor takminda

GS - Gaziantepspor macı sonucu Galatasaray Gaziantep maç özet ..

e-Haber Ajansi - 2 saat once

Galatasaray Gaziantep maç SONUCU OZET 1-0 Gs-Gaziantepspor ...

Haber Gazete - 3 saat önce
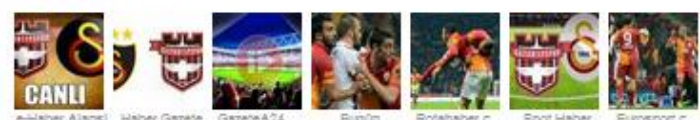

141 haber kaynağinn tümü :

Galatasaray Gaziantepspor maçı hanqi kanalda ne zaman

Star Gazate - 13 sast once

Gaziantepspor Galatasaray maçı ne zaman 2013. Galatasaray Gaziantepspor maçı ne zaman

hangi kanalda saat kaçta aynntlar.

Galatasaray Gaziantepspor maçı ne zaman bașlayacak? maç saat ....

GazeteA24, hem okumak hem izlemek iọin - 6 saat once

Galatasaray Gaziantepspor deplasmanna cokyor... Cimbom ligin bitimine 3 hafta kal

sampiyonluğunu ilan edebilir...GS Gaziantep maçını

+ Daha fazla göster

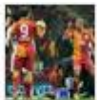

Futbol - Süper Lio Maç Merkezi: Gaziantepspor - Galatasaray

Gaziantepspor macı öncesi Galatasaray'da Wesley Sneijder in sakatlğı sürüyor. Hamit

Altntop ise san kart ceza sininnda bulunuyor.

\section{Galatasaray-Gaziantep maçında taraftarlara biber qazl}

Gaziantep - Galatasaray maçının oynanacağı Gaziantep teki Kamil Ocak Stadi nun d’şından

Şekil 7. Google News'te "Gaziantep Galatasaray" maçı aramaları

(Figure 7. "Gaziantep Galatasaray" match searches in Google News) 
Yukarıda ele alınan örneklerde de görüldüğü üzere; çevrimiçi ortamda yayın yapan her türden "haber sitesi", arama motorlarında ilgili konuyu arayan okuyucuları "çöp" haber hamleleri ile sitesine çekebilmenin uğraşı içerisindedirler. Gazetecilik mesleği ve çevrimiçi yayıncılığın geleceği açısından düşündürücü olan bu örnekler, başta okuyucular olmak üzere bu ortamda faal olan her kesimi rahatsız edecek boyutlara ulaşmıştır.

\section{SONUÇ (CONSLUSION)}

Internet gibi yeni ve interaktif medya teknolojileri gazetelerin geleneksel iş modellerini değiştirmiştir. Medya içeriği, haberler asla bir boşluk içerisinde üretilmemektedir. Haberleri ve gazeteciliği şekillendiren iç ve dış aktörler (medya patronları, siyasi-ekonomik çevre ve kâr grupları, reklamcılar, gazeteciler ve izleyiciler) haber üretim süreçlerini etkilemektedirler. Çevrimiçi ortam açısından bakıldığında da bu aktörlerin her birinin geleneksel ortamda sahip oldukları etki ve rollerde değişimler söz konusudur. İzleyici ölçümlerindeki gelişmelerle çok daha net bir izleyici profil bilgisine sahip olan reklamcıların etkinliğindeki artış dikkate değerdir (Strömback ve Karlsson, 2011). Bu artışla birlikte gazeteciler cephesinden daha fazla ziyaretçiye ulaşabilmek, içerikleri ona göre şekillendirmek önemli hale gelmiştir. Ekonomik çıkarlar ve rekabet olgularıyla çerçevelenen bu ortamda gazeteciler, izleyici kitlenin talep ve isteklerini dikkate alan ya da yeni ilgiler yaratan gazetecilik anlayışını uygulamaya koymuşlardır. Ancak henüz deneme yanılma aşamasındaki bu uygulamalar içerisinde geleneksel ortamlardan alışkın olmadığımız, gazetecilik değerleriyle ve etik ilkelerle çelişen durumlar söz konusudur.

Haber kurumları "mesleğin adil olma, bütünlük, denge ve doğruluk gelenekleri ile online izleyicilerin son dakika haber arzularını meşrulaştırma arasında denge kurabilmek için" bir mücadele vermektedir (Lasica'dan akt. Cohen, 2002:538). Internette yer alan binlerce haber sitesi için, içerik ve habercilik konusunda belirleyici olan görülen o ki ticari kaygılardır. Geleneksel düzende habercilik adına var olan içerik, format, etik, doğruluk, haber değeri ilkeleri çevrimiçi ortam açısından anlamını yitirmiş gözükmektedir. Yalnızca online olarak temsil edilen, internetin ortaya çıkışı ile türeyen tekno/beceri ürünü yüzlerce haber sitesi açısından bakıldığında bu durum bir derece anlamlı gözükebilecektir. Ancak geleneksel ortamdan tanıdığımız, belli bir kurumsal kültürü olan ana aklm aktörlerinin söz konusu değerler ve ilkeleri hiçe sayan uygulamalara ayak uydurmaları ve ticari kaygılarla haberciliği şekillendirmeleri, internet haberciliğindeki erimenin dozunu artırmaktadır.

Çevrimiçi yayıncılık açısından en önemli etik mesele, haber ile ticari enformasyon arasındaki sınırların belirsizleşmesidir. Geleneksel gazetecilik açısından bağımsızlık olgusu çok ciddiye alınan bir olgudur ve "habercilik" ve "ticaret" birbirinden açıkça ayrılmış alanlardır. Ancak bu durum çevrimiçi gazetecilik için her zaman geçerli bir durum değildir. Hemen hemen bütün internet medyası serbest erişime açıktır ve gelirlerini abonelik üzerinden değil reklâmlardan elde etmektedirler. Okuyucular, okudukları bir haberle, sayfada görüntülenen bir reklam ile ilgili siteye ekonomik kazanç sağladıklarının bazen farkında olmamaktadır. İnternet ortamındaki yayıncılığa yönelik eleştiriler; haber içeriği ile reklâmlar arasındaki bütün sınırların bulanıklaştığı ve haber tanımının değiştiği hususu üzerine odaklanmaktadır (Geray ve Aydoğan, 2010:314316; Evers, 2010:23). 
Internet haberciliğinin doğasında var olan "hipermetinsellik", ticari unsurlarla editöryal içeriğin bir arada sunulmasına imkân vermektedir. Haberlerle birlikte sunulan linkler, reklam bantları (banner) ya da kullanıcı inisiyatifi dışında ortaya çıkan pop-up türü açılır reklamlar, haberle reklam arasındaki çizgiyi giderek daha belirsiz hale getirmektedir (Cohen, 2002:541). Geleneksel ortamlarda reklamla karşılaşan izleyicinin sahip olduğu seçme özgürlüğü çevrimiçi ortamda sınırlandırılmış gözükmekte ve ziyaretçiler tercihleri dışında reklamlarla karşı karşıya kalabilmektedirler. Tek başına bu durum bile geleneksel gazetecilik ve etik değerleriyle bir çelişki oluşturmaktadır. Bu anlamda internet gazetelerinin kendine özgü "etik kodlar" geliştirmesi ve kurumsallığın izlerini taşıyan uygulamalara yer vermesi gerekmektedir. Reklam ile haberi birbirinden ayıracak gazetecilik standartları geliştirilmelidir.

Çalışmada ele alınan ve örnekleriyle sunulan "çöp" haber ve siteler, İnternet gazeteciliği açısından ortaya çıkan "güven kaybı"nı daha da derinleştirmektedir. Bu tür haber ve sitelerde yer alan sözde içerikler ne teorik ne de uygulama anlamında gazetecilik pratikleri içerisinde yer almamaktadır. Arama motorları gibi teknolojik mantıkla çalışan sistemlerle de, söz konusu site ve haberleri ortadan kaldırmak mümkün görünmemektedir. Kısa geçmişi dikkate alındığında henüz "deneyleme" aşamasında olduğu varsayılan internet gazeteciliğinin bu tür sorunları aşabilmesi, mesleki etik standartlar ve oto kontrol sistemlerine bağlı görünmektedir.

\section{TEŞEKKÜR (THANKS)}

Çalışmamıza ve trafik kaynaklarını anlamlandırmamıza yardımcı olan kurumsal veri niteliğindeki bilgileri paylaşımları dolayısıyla ankarahaber.com çalışanlarına teşekkür ederiz.

\section{KAYNAKLAR (REFERENCES)}

1. Currah, A., (2009). What's Happening to Our News, Reuters Institute for the Study of Journalism, University of Oxford, [Online:

https://reutersinstitute.politics.ox.ac.uk/fileadmin/documents/P ublications/What_s_Happening_to_Our_News.pdf, Erişim: 21 Aralık 2012]

2. Cuts, M., (2010). "How Search Works", http://www. youtube.com/watch?v=BNHR6IQJGZs, Erişim: 19 Ekim 2013.

3. Deuze, M., Bruns, A., and Neuberger, C., (2007). Preparing For An Age of Participatory News, Journalism Practice, 1:3, 322-338, [Online: http://dx.doi.org/10.1080/17512780701504864, Erişim: 12 Aralık 2012]

4. Dick, M., (2011). Murray Dick (2011). Search Engine Optimisation in UK News Production, Journalism Practice, 5:4, 462-477. [Online: http://dx.doi.org/10.1080/17512786.2010.551020, Erişim: 21 Aralık 2012]

5. Evers, H., (2010). "İnternet Haberciliği: Yeni Etik Sorunlar mı?", Televizyon Haberciliğinde Etik, Çaplı, B. ve Tuncel, H. (Ed), Fersa Yayınları, Ankara.

6. Geray, H. ve Aydoğan, A., (2010). "Yeni İletişim Teknolojileri ve Etik", Televizyon Haberciliğinde Etik, Çaplı, B. ve Tuncel, H. (Ed), Fersa Yayınları, Ankara.

7. Goldsborough, R., (2011). "Effective Google Searching Means Making Use of All Available Tools", Community College Week, March 7, 2011. [Online: http: //ehis. ebscohost. com/ehost/pdfviewer/pdfviewer?sid=d43f $45 \mathrm{cc}$ 
-e1d7-4620-bd5d-ab219e0218cc\%40sessionmgr115\&vid=1\&hid=104, [Erişim: 21 Aralık 2012]

8. Herbert, J. and Thurman, N., (2007). Paid Content Strategies For News Websites, Journalism Practice, 1:2, 208-226 [Online: http://dx.doi.org/10.1080/17512780701275523, Erişim: 20 Kasım 2012 ]

9. http://haber.stargazete.com/guncel/galatasaray-gaziantepspormaci-ozeti-golleri-10-izle/haber-749439, (Erişim: 30 Nisan 2013)

10. http://www.gazetea24.com/haber/gaziantep-galatasaray-maci-ozetizle-ligtv-gs-gaziantep-maci-ozeti-galatasaray-gaziantepspormaci-golleri-seyret-video-galatasaray-gaziantepspor-mac-sonucu1-0 23421107.html, (Erişim: 30 Nisan 2013)

11. http: //magazin.milliyet.com.tr/atv-canli-izle-kurtlar-vadisipusu-190-yeni-bolum-atv-den-canli-izle-25-nisan-2013persembe/magazin/magazindetay/25.04.2013/1698623/default.htm, (Erişim: 29 Nisan 2013)

12. Işık, U. ve Koz, K.A., (2009). "Cinsellik Üzerinden "Tık Ticareti": İnternet Haberciliği Üzerine Bir İnceleme", İletişim Kuram ve Araştırma Dergisi, Güz 2009, Sayı:29, Ankara.

13. Sebastian, M., (2013). "Study Suggests Fake Web Traffic Is Worse Than You Thought But Publishers Have Ways to Identify It", : http: / /adage.com/article/media/fake-web-traffic-costingadvertisers-billions/243544/ (Erişim Tarihi: 20 Ekim 2013)

14. Strömbäck, J. and Karlsson, M., (2011). Who's Got The Power?, Journalism Practice, 5:6, 643-656, [Online: http://dx.doi.org/10.1080/17512786.2011.592348, Erişim: 12 Aralık 2012]

15. Ward, S.J.A. and Wasserman, H., (2010). Towards an Open Ethics: Implications of New Media Platforms for Global Ethics Discourse, Journal of Mass Media Ethics: Exploring Questions of Media Morality, 25:4, 275-292, [Online: http://dx.doi.org/10.1080/08900523.2010.512825, Erişim Tarihi: 12 Kasım 2012] 